\title{
The effect of ENEAS application in patients with endometriosis and its influence on the level of IL-8 and MCP-1
}

\author{
Denghui Liang1, Yuhong Zhang ${ }^{1}$, Lihua Chen ${ }^{1}$, Lisha Shu' ${ }^{1}$ Ying $\mathrm{He}^{1}$, Hui Ma ${ }^{1}$, Mei Qiao² ,Denghui \\ Liang $^{1^{*}}$, Na Wang ${ }^{2^{*}}$ \\ 1.Department of Gynaecology and Obstetrics, The First Affiliated Hospital of Hebei North University, Zhangiakou, Hebei Province, \\ China \\ 2.Department of Gynaecology and Obstetrics, The Fouth Hospital of Shijiazhuang, Obstetrics and Gynaecology Hospital Affiliated to \\ Hebei Medical University Shijiazhuang, Hebei Province, China
}

\section{ARTICLE INFO}

\section{Original paper}

Article history:

Received: August 09,2021

Accepted: November 10, 2021

Published: December 01, 2021

\section{Keywords:}

Database; Endometriosis;

ENEAS, Interleukin-8;

Monocyte; Chemoattractant Protein-1 \begin{abstract}
Endometriosis is a gynecological disease that endometrial cells develop outside the uterus. This event happens when the endometrial glands grow outside the endometrium and uterine muscles, especially in the pelvis. Although endometriosis is widespread, the clinical manifestations of the disease are very different, and it is challenging to adapt to the conventional classification system to divide patients into homogeneous groups. Given the importance of endometriosis, a correct, accurate, and timely diagnosis of this disease can significantly prevent its complications. Using health-related software is one of these ways. Enhanced Endometriosis Archiving Software (ENEAS) is a web-based application based on one of the most widely used open-source database management systems (MySQL), allowing the direct link to other open-source software for data management and storage. In the current study, the effect of ENEAS application was considered in patients with endometriosis, and its influence on IL-8 and MCP-1 gene expression was evaluated. For this purpose, 100 women with endometriosis were divided into two groups of 50 patients. The first group (control group) was examined by a gynecologist and received medication and treatment. In the case group, their demographic and clinical information were entered into ENEAS software. To study the expression of the IL- 8 gene and MCP-1 gene, after collecting $5 \mathrm{ml}$ of blood samples in tubes containing anticoagulant, RNA extraction was performed by Total RNA Purification Kit (Cat. 17200, 37500, 17250). Then cDNA synthesis was performed for this purpose, and a Bioneer DNA synthesis kit (South Korea) was used. The results showed that the expression level of the IL-8 gene in the case group was significantly reduced compared to the control group $(\mathrm{P}=0.035)$. MCP-1 gene expression was also decreased compared to the control group, but this decrease was not significant. Therefore, those who used this application for treatment had reduced expression of IL-8 and MCP-1 genes. This event indicates that this application has reduced the amount of inflammation caused by endometriosis with proper analysis.
\end{abstract}

DOI: http://dx.doi.org/10.14715/cmb/2021.67.4.38 Copyright: (C) 2021 by the C.M.B. Association. All rights reserved. (c) (i)

\section{Introduction}

Endometriosis is a gynecological disease characterized by the presence and growth of endometrial glandular tissue and stroma outside its original location (uterine cavity) (1). Endometrial tissue deposition is most common in the pelvis (ovaries, peritoneum, uterosacral ligament, Douglas space, rectovaginal septum) (2). Endometriosis is a common disease of reproductive age; it is found in $10 \%$ of fertile women and $50-20 \%$ of infertile women (1). This common disorder is a chronic inflammatory disease associated with a general inflammatory response in the peritoneal cavity and it is called a disease with an immunological background (3). The etiological immune/inflammatory cause of endometriosis is related to increased concentrations of activated macrophages, cytokines, $\mathrm{B}$ and $\mathrm{T}$ cells, growth factors, and angiogenesis stimulators. Angiogenesis is essential pathophysiology in the development of endometriosis (4).

Vascular endothelial growth factor (VEGF) is a critical mediator in angiogenesis and has strong potential in physiological and pathological angiogenesis. This disorder is one of the most wellknown conditions for changes in angiogenesis (5). The expression of many other angiogenic growth factors and cytokines (FGF, IGF, PGF, IL-1, and IL8) has also increased in the endometrial tissue of women with endometriosis (6-8). Monocyte chemotactic protein-1 (MCP1) is produced by monocytes, endothelial cells, fibroblasts, and $\mathrm{T}$ cells increasing the migration of monocytes from the bloodstream to tissue and converting them to macrophages (8). It eliminates infection from the body 
by inducing phagocytosis. MCP1 is a member of the cytokine family and plays a vital role in the secretion, release, and function of monocytes, macrophages, neutrophils, and lymphocytes (9). This cytokine is involved in the immune response to infection and inflammation and has antitoxic effects following the administration of drugs. It has different functions depending on the target organ, the dose of the medicine, the role of other cytokines, and drug administration. For example, MCP stimulant medicines are used in the lungs, while MCP blocker medicines are used in the kidney and endometriosis disease $(10,11)$

The most proper diagnostic and treatment methods have not yet been identified for endometriosis, and the management of this chronic disease is complex in most cases $(2,12)$. For endometriosis research, high costs and expertise are needed to collect reliable and detailed clinical history, imaging data, and the processing of tissue specimens (12). Such information is of the most incredible value when collected using systematic protocols and accompanied by detailed clinical classification/cataloging of patients (13). Therefore, developing a global registry of endometriosis bio-banks and databases is one of the main priorities for endometriosis research. For this purpose, Enhanced Endometriosis Archiving Software (ENEAS) has been developed as the first databank to store, retrieve, compare, and correlate data collected on the management of patients diagnosed or suspected endometriosis in different centers (14).

Based on the importance of health-related software (14), this study investigated the effect of ENEAS application on the expression of IL-8 and MCP-1 genes in patients with endometriosis.

\section{Materials and methods \\ Studied patients}

In this case-control study, 100 women with endometriosis were divided into two groups of 50 patients. The first group (control group) was examined by a gynecologist and received medication and treatment. In the case group, their demographic and clinical information were entered into ENEAS software. According to the database prepared in this software, the type and amount of medicines were determined, and after approval by a gynecologist, they were treated. Two months after treatment, blood samples were taken from these individuals for further evaluation.

\section{Genetic evaluations}

To study the expression of IL- 8 and MCP- 1 gene, after collecting $5 \mathrm{ml}$ of blood samples in tubes containing anticoagulant, RNA extraction was performed by Total RNA Purification Kit (Cat. 17200, $37500,17250)$, and then cDNA synthesis was performed for this purpose and Bioneer DNA synthesis kit (South Korea) was used. All steps were performed on ice and under the Laminar flow cabinet and sterile conditions. After RNA extraction and cDNA synthesis, the PCR reaction was performed in a volume of $10 \mu 1.5 \mu 1$ of Mastermix 2X, $3 \mu 1$ of DEPC, $1 \mu 1$ of cDNA, and $0.5 \mu l$ of primer were added to each micro-tube. Allele ID software was used to design the primers, and they were synthesized by BioTech (USA). The Beta-actin gene was used as a housewife gene to normalize the data. The sequence of primers is given in Table 1. The PCR program is listed in Table 2. DNAs were amplified by Comfort Thermocycler (Eppendorf, Germany).

Table 1. The Sequence of the primers designed with Allele ID software; gene (A), primer sequence (B), and annealing temperature $(\mathrm{C})$

\begin{tabular}{lcrc}
\hline $\mathrm{A}$ & & $\mathrm{B}$ & $\mathrm{C}$ \\
\hline $\mathrm{IL}-8$ & Forward & 5'-TCTCTTGGCAGCCTTCCT-3' & $52^{\circ} \mathrm{C}$ \\
& Reverse & 5'-ACTGAACCTGACCGTACATGT-3' & \\
MCP-1 & Forward & 5'-CTGCTTGCTGCCATTCTC-3' & $58^{\circ} \mathrm{C}$ \\
& Reverse & 5'-CACACCTGCCTTTACACC-3' & \\
\multirow{3}{*}{-Actin } & Forward & 5'-CCTCGCTCTCCACCTTCC-3' & $61^{\circ} \mathrm{C}$ \\
& Reverse & 5'-TGCCAATCTCGTCTCGTTTC-3' & \\
\hline
\end{tabular}

Table 2. Time and temperature of the real-time PCR cycles

\begin{tabular}{lccc}
\hline Steps & Time & Temperature & Cycles \\
\hline Primary & 10 minutes & $95^{\circ} \mathrm{C}$ & 1 \\
Denaturation & & $95^{\circ} \mathrm{C}$ & 35 \\
Denaturation & 15 seconds & $52^{\circ} \mathrm{C}-61^{\circ} \mathrm{C}$ & 35 \\
Annealing & 30 seconds & $72^{\circ} \mathrm{C}$ & 35 \\
Extension & 30 seconds & \\
\hline
\end{tabular}

\section{Statistical analysis}

For statistical analysis of data, SPSS software version 18 was used. Paired t-test was performed on the expression of MCP-1, IL- 8 , and beta-actin genes in both groups. $P$-value less than 0.05 were considered significant. 


\section{Results and discussion}

\section{Demographic and clinical evaluations}

The mean and standard deviation of women age in the case group (33.72 \pm 0.61 years) had a significant difference compared to the control group (34.85 \pm 0.71 years $)(P=0.025)$ (Table 3$)$. The mean and standard deviation of body mass index of the case and control women were $24.78 \pm 0.23 \mathrm{~kg} / \mathrm{m}^{2}$ and $19.33 \pm 0.42 \mathrm{~kg} / \mathrm{m}^{2}$ $(\mathrm{P}=0.048)$, respectively. The frequency of infertility in the case group was almost equal to the control group so that $36 \%$ of the control group and $34 \%$ of the treatment group had infertility $(\mathrm{P}=0.699)$. Painful menstruation was not significantly different between the two groups.

Table 3. Demographic and clinical evaluations in control group and case group

\begin{tabular}{|c|c|c|c|}
\hline Variable & $\begin{array}{l}\text { Control Group } \\
(\mathrm{n}=50)\end{array}$ & $\begin{array}{l}\begin{array}{l}\text { Case Group } \\
(\mathrm{n}=50)\end{array} \\
\end{array}$ & P-value \\
\hline Age (year) & $34.85 \pm 0.71$ & $33.72 \pm 0.61$ & 0.025 \\
\hline BMI $\left(\mathrm{kg} / \mathrm{m}^{2}\right)$ & $19.33 \pm 0.42$ & $24.78 \pm 0.23$ & 0.048 \\
\hline \multicolumn{4}{|l|}{ Marital Status } \\
\hline Married & $43(86 \%)$ & $45(90 \%)$ & 0.421 \\
\hline Single & $7(14 \%)$ & $5(10 \%)$ & 0.447 \\
\hline Infertility & $17(34 \%)$ & $18(36 \%)$ & 0.699 \\
\hline \multicolumn{4}{|l|}{ Regular } \\
\hline \multicolumn{4}{|l|}{ Menstruation } \\
\hline Having & $28(56 \%)$ & $26(52 \%)$ & 0.112 \\
\hline Not Having & $22(44 \%)$ & $24(48 \%)$ & 0.098 \\
\hline \multicolumn{4}{|l|}{$\begin{array}{l}\text { Duration of } \\
\text { menstrual } \\
\text { bleeding }\end{array}$} \\
\hline$\leq 4$ days & $11(22 \%)$ & $12(24 \%)$ & 0.672 \\
\hline 5 days & $25(50 \%)$ & $24(48 \%)$ & 0.721 \\
\hline$\geq 6$ days & $14(28 \%)$ & $14(28 \%)$ & 1 \\
\hline \multicolumn{4}{|l|}{ Menstrual Pain } \\
\hline Having & $35(70 \%)$ & $33(66 \%)$ & 0.72 \\
\hline Not Having & $15(30 \%)$ & $17(34 \%)$ & 0.78 \\
\hline $\begin{array}{l}\text { premenstrual } \\
\text { spotting } \geq 2 \text { days }\end{array}$ & $31(62 \%)$ & $32(64 \%)$ & 0.901 \\
\hline \multicolumn{4}{|l|}{ Family History } \\
\hline Having & $41(82 \%)$ & $37(74 \%)$ & 0.077 \\
\hline Not Having & $9(18 \%)$ & $13(26 \%)$ & 0.061 \\
\hline
\end{tabular}

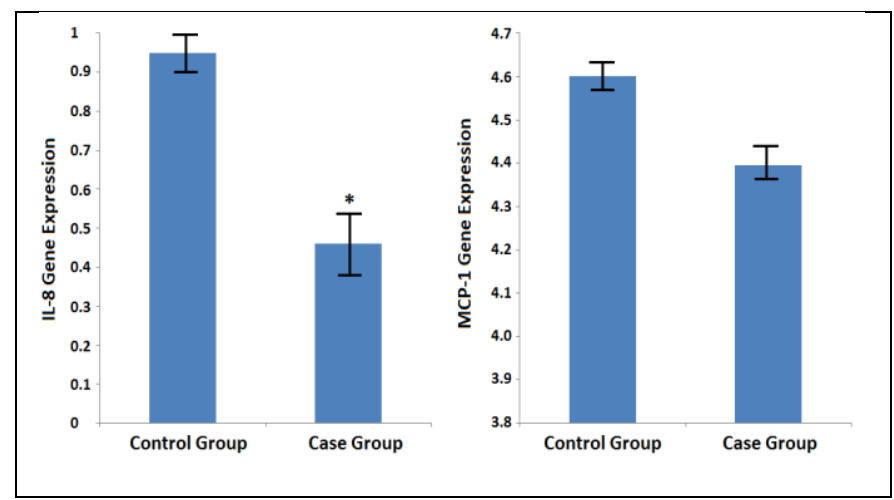

Figure 1. The relative IL-8 gene and MCP-1 gene Expression in control group and case group

\section{Genetic evaluations}

This part showed that the expression level of the IL-8 gene in the case group was significantly reduced compared to the control group $(\mathrm{P}=0.035)$ (Figure 1). MCP-1 gene expression was also decreased compared to the control group, but this decrease was not significant.

Endometriosis refers to the growth of endometrial tissue outside the uterine cavity, which can occur inside and outside the pelvis (1). Endometriosis is most common in the pelvis, ovaries, posterior clavicle, uterine ligaments, pelvic peritoneum, and rectovaginal septum (15). When endometriosis is found in other body parts, such as the cervix, vulva, vagina, intestines, urinary system, abdominal wall, chest, lungs, and central nervous system, ectopic endometriosis will occur. Although many patients with endometriosis have no symptoms, they may be associated with menstrual cramps, intercourse pain, and chronic pelvic pain (16). Endometriosis is also seen in 30 to $50 \%$ of infertile women, which was similar to the results of our study. Causes of endometriosis include infertility, family history of endometriosis, obstruction of the normal outflow of menstrual blood from the body, history of pelvic infection, and uterine disorders (8). Accurate and reliable results of the leading causes of the disease are not available. Still, according to researches, in addition to environmental factors, hereditary factors also play an essential role in endometriosis in people with first or second-degree relatives. The risk of endometriosis is significantly increased in them (2). The results of our study also showed that $82 \%$ of the control group and $72 \%$ of the case group had a family history.

In the study by Burghaus et al. (17), which was performed as a case-control study and by using logistic regression model, the age of menarche onset, menstrual period, menstrual cycle length, number of pregnancies, ectopic pregnancies, and smoking were considered as risk factors. In line with the results of our study, which showed that $62 \%$ of the control group and $64 \%$ of the case group had premenstrual spotting, Hardiman et al. (18) showed that premenstrual spotting for two days or more was associated with endometriosis, which is identified as a better predictor than painful menstruation and painful 
proximity. A study by Potischman et al. (19) found that high estrogen levels in the body significantly increased the risk of developing endometriosis. They also noted that estrogen levels were not associated with other factors in the occurrence of endometriosis and were an independent factor.

Given the importance of endometriosis, a correct, accurate, and timely diagnosis of this disease can significantly prevent its complications using healthrelated software is one of these ways (20). Enhanced Endometriosis Archiving Software (ENEAS) is a web-based application based on one of the most widely used open-source database management systems (MySQL), allowing the direct link to other open-source software for data management and storage (14). ENEAS can be installed locally on the server, which provides access to the database and any related functions through any computer connected to the local network (14). It can be used in a single hub or the Cloud without a local hardware load, allowing unacknowledged data to be shared in real-time and quickly used for research. Each patient has a personal form completed at the initial consultation within ENEAS and includes all relevant information, including name, nationality and date of birth, address, telephone number, and email address. Some of these are mandatory for further data entry. The classic website organization is chosen for the database collection, with a navigation bar on the left that allows the operator to move between macro events and their subsets quickly. The navigation bar includes clinical history, hospitalization, gynecology, outpatient counseling, and questionnaire. According to this application, patient data is stored, and comparing this data with the data of thousands of patients with endometriosis gives an overview of the disease to the obstetrician and the type and amount of medication easily obtained through this application (14). Evaluation of the performance of this application showed that the expression level of the IL-8 gene was significantly reduced. MCP-1 gene expression also decreased, but this decrease was not significant.

Interleukin 8 (IL-8) is a factor secreted by $\mathrm{T}$ lymphocytes that precisely differentiates $\mathrm{B}$ lymphocytes into plasma cells (producing antibodies) and is produced and secreted by hematopoietic and non-hematopoietic cells (21). Immunohistochemical studies on the human ovary have shown that IL- 8 is secreted from the corpus luteum (22). IL-8 causes follicogenogenesis and steroidogenesis in granulosa cells. IL-8 also promotes new angiogenesis in the human ovary by increasing the production and secretion of VEGF (23). Therefore, its excessive increase can cause the pathological complication of ovarian hyperstimulation syndrome. It has also been reported that the concentration of IL-8 increases in the follicular fluid of infertile women with endometriosis. Therefore, this cytokine can play a role in the pathogenesis of infertility due to endometriosiss (24, 25).

The results of this study showed that the use of ENEAS software enables gynecologists to compare the information of one patient to thousands of endometriosis patients in the software database, which can provide more accurate information for better treatment.

\section{Conclusions}

Endometriosis is a condition in which cells similar to endometrial cells develop outside the uterus. This event happens when the endometrial glands grow outside the endometrium and uterine muscles, especially in the pelvis. Although endometriosis is widespread, the clinical manifestations of the disease are very different, and it is challenging to adapt to the conventional classification system to divide patients into homogeneous groups. In addition, the lack of standardization of surgery and postoperative treatment poses a challenge for accurate comparison of data. It increases the number of possible subtypes related to the initial preoperative diagnosis. Therefore, developing a global registry of endometriosis biobanks and databases is one of the main priorities for endometriosis research. For this purpose, Enhanced Endometriosis Archiving Software (ENEAS) has been developed as the first databank to store, retrieve, compare, and correlate data collected on the management of patients diagnosed or suspected endometriosis in different centers. In the current study, the effect of ENEAS application was considered in patients with endometriosis, and its influence on the level of IL- 8 and MCP-1 gene expression was evaluated. The results showed that those who used this application for treatment had decreased expression of IL- 8 and MCP- 1 genes. This event indicates that this application has reduced the 
amount of inflammation caused by endometriosis with proper analysis.

\section{References}

1. Taylor HS, Kotlyar AM, Flores VA. Endometriosis is a chronic systemic disease: clinical challenges and novel innovations. Lancet 2021; 397(10276): 839-852.

2. Missmer SA, Tu FF, Agarwal SK et al. Impact of endometriosis on life-course potential: a narrative review. Int J Gen Med 2021; 14: 9.

3. Zoure AA, Bayala B, Bambara HA et al. Epidemiological Situation and Medical Management of Gynaecological and Breast Cancers from 1998 to 2018 in West Africa: A Systematic Review. Asian Pac j cancer biol 2020; 5(4): 211-219.

4. Wuyung PE, Rahadiati FB, Hartono Tjahjadi SS, Kusmardi K, Kodariah R, Wiweko B. Histopathology and ARID1A Expression in Endometriosis-Associated Ovarian Carcinoma (EAOC) Carcinogenesis Model with Endometrial Autoimplantation and DMBA Induction. Asian Pac J Cancer Prev 2021; 22(2): 553.

5. Dehghani $S$, Nosrati $R$, Yousefi $M$ et al. Aptamer-based biosensors and nanosensors for the detection of vascular endothelial growth factor (VEGF): A review. Biosens Bioelectron 2018; 110: 23-37.

6. Masoud Tourang LF, Yuan Zhong, Ram Chandra Suthar. Association between Human Endogenous Retrovirus K gene expression and breast cancer. Cell Mol Biomed Rep 2021; 1(1): 7-13.

7. Temtanakitpaisan A, Kleebkaow P, Aue-aungkul A. Epithelial Borderline Ovarian Tumor: Clinicopathological Features, Outcome and Prognostic Factors. Asian Pac j cance care 2018; 3(4): 75-75.

8. Nanda A, Thangapandi K, Banerjee $\mathrm{P}$ et al. Cytokines, angiogenesis, and extracellular matrix degradation are augmented by oxidative stress in endometriosis. Ann Lab Med 2020; 40(5): 390-397.

9. Matkar PN, Ariyagunarajah R, Leong-Poi $\mathrm{H}$, Singh KK. Friends turned foes: angiogenic growth factors beyond angiogenesis. Biomolecules 2017; 7(4): 74

10. Lin CI, Chen $\mathrm{CN}$, Chen JH, Lee $\mathrm{H}$. Lysophospholipids increase IL-8 and MCP-1 expressions in human umbilical cord vein endothelial cells through an IL-1-dependent mechanism. J Cell Biochem 2006; 99(4): 1216-1232.

11. Takaishi H, Taniguchi $\mathrm{T}$, Takahashi A, Ishikawa Y, Yokoyama M. High glucose accelerates MCP-1 production via p38 MAPK in vascular endothelial cells. Biochem Biophys Res Commun 2003; 305(1): 122-128.

12. Mounsey A, Wilgus A, Slawson DC. Diagnosis and management of endometriosis. Am Fam Physician 2006; 74(4): 594-600.

13. Andres MP, Arcoverde FV, Souza CC, Fernandes LFC, Abrão MS, Kho RM. Extrapelvic endometriosis: a systematic review. J Minim Invasive Gynecol 2020; 27(2): 373-389.

14. Centini G, Zannoni L, Lazzeri L et al. Enhanced Endometriosis Archiving Software (ENEAS): an application for storing, retrieving, comparing, and sharing data of patients affected by endometriosis integrated in the daily practice. J Minim Invasive Gynecol 2017; 24(3): 494-500.

15. Brilhante AVM, Augusto KL, Portela MC et al. Endometriosis and ovarian cancer: an integrative review (endometriosis and ovarian cancer). Asian Pac J Cancer Prev 2017; 18(1): 11.

16. Verit FF, Yucel O. Endometriosis, leiomyoma and adenomyosis: the risk of gynecologic malignancy. Asian Pac J Cancer Prev 2013; 14(10): 5589-5597.

17. Burghaus S, Klingsiek P, Fasching P et al. Risk factors for endometriosis in a German case-control study. Geburtshilfe Frauenheilkd 2011; 71(12): 10731079.

18. Hardiman P, Pillay OS, Atiomo W. Polycystic ovary syndrome and endometrial carcinoma. Lancet 2003; 361(9371): 1810-1812.

19. Potischman N, Hoover RN, Brinton LA et al. Case - control study of endogenous steroid hormones and endometrial cancer. J Natl Cancer Inst 1996; 88(16): 1127-1135.

20. Khezri H, Rezaei P, Askarian F, Ferdousi R. Developing a Web-based repository of evaluation tools for health-related software. Libr Hi Tech News 2021.

21. Fousek K, Horn LA, Palena C. Interleukin-8: A chemokine at the intersection of cancer plasticity, angiogenesis, and immune suppression. Pharmacol Ther 2021; 219: 107692.

22. Ohtsu A, Tanaka H, Seno K, Iwata $H$, Kuwayama T, Shirasuna K. Palmitic acid stimulates 
interleukin-8 via the TLR4/NF-kB/ROS pathway and induces mitochondrial dysfunction in bovine oviduct epithelial cells. Am J Reprod Immunol 2017; 77(6): e12642.

23. Tarumi $\mathrm{Y}$, Mori $\mathrm{T}$, Okimura $\mathrm{H}$ et al. Interleukin-9 produced by helper $\mathrm{T}$ cells stimulates interleukin-8 expression in endometriosis. Am J Reprod Immunol 2021; 86(3): e13380.

24. Kazemi E, Zargooshi J, Kaboudi M, Heidari P, Kahrizi D, Mahaki B, Mohammadian Y, Khazaei H, Ahmed K. A genome-wide association study to identify candidate genes for erectile dysfunction. Brief Bioinforma 2021; 22(4):bbaa338. https://doi.org/10.1093/bib/bbaa338

25. Malvezzi $\mathrm{H}$, Hernandes $\mathrm{C}$, Piccinato $\mathrm{CA}$, Podgaec S. Interleukin in endometriosis-associated infertility-pelvic pain: Systematic review and metaanalysis. Reproduction 2019; 158(1): 1-12.Keum N, Giovannucci E. Global burden of colorectal cancer: emerging trends, risk factors and prevention strategies. Nature reviews Gastroenterology \& hepatology 2019, 16(12):713-732. 